\title{
Verzeichnis der Redner
}

Achterberg S. 153

Badura S. 337, 349, 382, 388, 391, 392, 402

Berg S. 370

Bernhardt S. 131, 157

Blümel S. 171, 379, 400

Bothe S. 148

Breuer S. 385

Brohm S. 164, 360

Bullinger S. 362

Burmeister S. 363

Delbrück S. 156

Dicke S. 150

Doehring S. 147, 378

Fleiner S. 338

Frotscher S. 394

Frowein S. 110, 127, 130, 147, 159, 170

Geck S. 142, 159

Grabitz S. 132, 159

Grawert S. 277, 381, 397

Grewe S. 136

Häberle S. 129, 163, 356

Ipsen, Hans Peter S. 151

Kirchhof S. 383

Kisker S. 361

Knemeyer S. 365, 384

Kopp S. 158

Mayer, Franz S. 371, 389

Mayer-Tasch S. 385

Meessen S. 128, 161

Meyer, Hans S. 354, 389, 395

Müller, Jörg Paul S. 110

Mußgnug S. 154

Ossenbühl S. 373

Partsch S. 127

Püttner S. 374, 391

Rill S. 342

Roellecke S. 165

Saladin S. 396

Sattler S. 162

Scheuner S. 353 
Schmidt, Reiner S. 65, 146, 166

Schneider, Hans-Peter S. 377

Scholz S. 358

Siedentopf S. 387

Soell S. 375

Starck S. 388

Suhr S. 164

Thieme S. 391

Tomuschat S. 7, 145, 167

Vogel S. 145, 163

Wagener, Frido S. 366

Wielinger S. 393

Winkler S. 119

Zacher S. 134, 349

Zieger S. 139

Zippelius S. 395 